The final interview, with Françoise Vergès, concerns the relation between the social and the formation of empire. She argues that the constitution of the social in modernity was closely connected with colonial relations. The interview draws attention to the continuation of the model of colonization today in the new spaces created by globalization. In the grey zones of globalization are to be found 'postcolonial colonies'. Her hypothesis is that processes of creolization exist alongside other processes produced by globalization, which entails not just networks and contacts, but also conflict. Indeed, the distinctive feature of creolization is violence and it signals an entirely different conception of the social than that in modern sociology.

As interviews, we do not get fully worked out answers to complex and challenging questions. The volume does succeed in its aim in orienting critical thinking and promoting debate and further questions. The interviews are excellently edited and contain much that is new. The only criticism that can be made is that the problematic of globalization tends to overshadow other dimensions of the contemporary challenge to social theory.

Gerard Delanty University of Liverpool, UK.

\author{
The Philosophical Foundations of Environmental Law \\ Sean Coyle and Karen Morrow \\ Hart Publishing, Oxford and Portland, 2004, xv + 228pp. \\ ISBN: 1841133604.
}

Contemporary Political Theory (2005) 4, 338-340. doi:10.1057/palgrave.cpt.9300202

Most writings about environmental law read it narrowly, with an assumption that it is merely an instrumental response to the contemporary problems of environmental management. Rarely do writers investigate the deeper philosophical currents that shape environmental law and its applications. In a very compact discussion, the authors have gone far beyond this limited view and attempted to link the substance and structure of current environmental law with broader changes in the philosophical treatment of human-nature relationships. The writing is dense but not inaccessible, and the authors have made a conscious attempt to keep the reader oriented to their thesis. The difficulties primarily reside in the authors' attempt to make a broad statement about environmental law which, in fact, is limited to common law and most particularly to the English experience. This criticism is offset by the care that 
the authors have used in constructing a legal and philosophical history, and in weaving together the broad historical development of ideas about property and rights with the more narrow legal treatment of these same subjects.

At the beginning, the authors state that their primary purpose is to demonstrate that contemporary environmental law is the end result of longterm changes in political thinking about the environment that began with a moral rather than an instrumental view. However, there is also a subtext to the argument that links this philosophical shift to structural changes in political economy, such as the rise of mercantilism, capitalism and urbanization. The argument is organized into four sections (Chapters 2-5), with subsections that guide the reader through the principal points. The first section explores how English common law developed from a valuing of nature to a treatment of nature as property, in which the authors traverse a broad terrain of political thinking from Grotius' concern for human culture through Rousseau and Locke's treatment of private property rights and on to Blackstone and the development of the 'science' of law. It is a very ambitious discussion but one that works because the authors remain on point.

In the second section, the authors continue to develop their thesis through a condensed discussion of mercantilism and primitive capitalism, and their reshaping of legal theory generally. It is a discussion consumed with the tensions between common law legal traditions of justice and equity, and the emerging requirements of industrial capitalism and its need for utilitarian access to resources. The discussion over-reaches at times, but creates a sense of how the socio-political forces overwhelm traditional ways of organizing communities and the laws that govern them. This section, perhaps, is most useful in raising questions about the development of law, such as the influence of positivism, and should be read broadly as an overview rather than a definitive study of any of these issues.

The authors are on firmer ground when they move into a more bounded discussion in the third section, where they discuss how contemporary environmental issues have been formed into questions of law. They largely succeed in presenting what can be arcane legal analysis as clear academic prose, and in showing how environmental issues have become creatures existing within the common law categories of contract, nuisance, and tort. The use of non-legal writings as supplements to the discussions of statutes and case law help secure the linkages between law, politics, and philosophy, which can be seen in the national and international environmental regimes that currently punctuate environmental policy. It also facilitates the authors' argument that current environmental law is nothing more than an attempt to 'trace out the relationships which hold between concepts such as property, right and responsibility in the context of environmental management' (p. 200). 
The authors, however, are on less firm footing when they attempt to apply their legal analysis to present day environmental politics in the last section. Their narrow focus locates law and policy regimes as operating primarily within a common law culture, and only peripherally acknowledges other influences. This is a Euro-centric view that loses considerable power as it moves beyond the continent and into an ever-increasingly global environmental politics. A good case has been made by a wide range of 'Green' political theorists that environmental law has strong cultural, social, and political qualities that dilute its effect as it moves beyond its initial boundaries. Similarly, critical environmental policy studies suggest that legal prescriptions are modified, and sometimes redefined, by internal institutional politics, external community politics, and the malleable nature of discourse.

Specific criticisms of the limits of this book should not be exaggerated. The authors make an admirable effort to cast new light into a key aspect of environmental politics, and largely succeed in connecting threads of ideas about nature and human relationships by weaving together 400 years of common law history into a seamless web of environmental thought and legal regulation. It is a timely and important thesis because it brings together philosophy, political theory and environmental politics in a way that should raise questions and encourage new ways of thinking about these subjects as a connected whole. It also offers insights into how we have constructed and may yet reconstruct our collective relationships with nature.

Darrell Whitman

Keele University, UK.

\section{The Tragic Vision of Politics: Ethics, Interests and Orders}

Richard Ned Lebow

Cambridge University Press, Cambridge, 2003, 405pp.

ISBN: 0521534852

Contemporary Political Theory (2005) 4, 340-342. doi:10.1057/palgrave.cpt.9300203

Political realism has never been an easy position to define, or to defend. In public discourse, it exhibits a definitional flexibility that often leads to crude ideological manipulation and banal partisanship. In International Relations, where 'Realism' stands as one of the theoretical pillars of the field, it has in recent years been reduced to little more than a general concern with 'power 